\title{
CHINA-BRASIL, UNA COMPARACIÓN INSTRUCTIVA $^{1}$
}

Pierre Salama

Un marciano llega a la Tierra. Habiendo estudiado las recomendaciones de las instituciones internacionales y visitado China y Brasil, nuestro marciano no entiende por qué China presenta una tasa de crecimiento elevada mientras que ni sus instituciones, ni su gobernanza, ni la política económica elegida por las autoridades corresponden a los cánones definidos por el Banco Mundial; o que otros países como Brasil, habiendo seguido, con más o menos reticencias, sus recomendaciones, no consiguen llegar a la golden age de China. ${ }^{2}$ Dos trayectorias diferentes; de ahí el interés de compararlas.

Si comparar no es suficiente, sí permite imaginar. No se trata entonces de proponer que Brasil "le copie" a China para obtener una tasa de crecimiento más elevada; las condiciones históricas, políticas y socioculturales son totalmente diferentes, y sería particularmente ingenuo pensar que podría hacerlo. De forma más realista, entre las numerosas cuestiones, se trata de entender por qué la tasa de inversión es elevada en un caso y débil en el otro, por qué en China parecen estarse afianzando comportamientos schumpeterianos y en Brasil, rentistas, y, a partir de un diagnóstico tal, ver si es posible impulsar más comportamientos schumpeterianos y menos comportamientos rentistas. Contrario a las ideas impuestas -la famosa "there is no alternative" de Thatcher-, comparar

${ }^{1}$ Conferencia pronunciada en El Colegio de México en diciembre de 2014.

${ }^{2}$ D. Rodrick, "Growth Strategies", en Ph. Aghion y S. Durlauf (dirs.), Handbook of Economic Growth, vol. 1, Elsevier, 2005. 
permite entender que existen alternativas; la imaginación se nutre de la comparación. El objeto de la exposición que sigue es entender el despegue de los países emergentes en los años 2000, en particular de China y de Brasil, así como los límites de sus respectivos patrones de crecimiento.

La década de 2000 es interesante por tres motivos: de inicio, porque parece confirmarse un proceso de convergencia con las economías avanzadas del que se benefician, sobre todos los países emergentes, los países asiáticos; luego, porque las rutas que se emprendieron son muy diferentes en China y en Brasil; finalmente, porque esas vías parecen estarse agotando, perdiendo su dinamismo y, en consecuencia, se abre un nuevo periodo lleno de interrogantes.

\section{ECONOMÍAS EMERGENTES, ¿QUE ENGLOBA ESTA APELACIÓN?}

\subsection{Una convergencia con los países avanzados que se acelera y luego tiende a agotarse}

En el transcurso de los años 1960 a 2000, cerca de $29 \%$ de los países desarrollados presentan una tasa de crecimiento media del PIB superior al 1.53 de Estados Unidos. En el transcurso de los años 2000 a 2011, ese porcentaje aumenta considerablemente: $90 \%$ de los países en desarrollo tienen una tasa de crecimiento superior a la de Estados Unidos, de 2.94\%, según datos del Banco Mundial. Se desencadena un proceso de convergencia: la brecha entre los niveles del pIB de muchos países del Sur y del Norte se reduce. Esto concierne sobre todo a los países emergentes asiáticos y, con el alza del precio de las materias primas, a algunos países africanos. En conjunto, el diferencial entre las tasas de crecimiento refleja un movimiento de convergencia de los niveles de ingreso per cápita entre países del Sur y del Norte. El ejemplo de los BRIC (Brasil, Rusia, la India y China) ilustra bien este fenómeno de convergencia. El peso económico de los BRIC representa, en el 2000, $16.39 \%$ del PIB mundial, estimado con el tipo de cambio de paridad de poder adquisitivo de 2005 , y en $2012,27.11 \%$, gracias sobre 
todo al fuerte crecimiento de China y de la India, según la base de datos del Fondo Monetario Internacional (2013). El peso de China en el PIB mundial pasa de $7.12 \%$ (contra $23.49 \%$ de Estados Unidos), en 2000, a 14.52\% (contra $18.87 \%$ de Estados Unidos) en 2012; el de la India pasa de 3.71 a $5.63 \%$, el de Brasil de 2.91 a $2.83 \%$ y el de Rusia de 2.65 a $3.02 \%$. Calculado con el tipo de cambio de paridad de poder adquisitivo, el PIB de China sobrepasa al de Estados Unidos en 2014 y, a nivel per cápita, se avecina al de Brasil, es decir, un cuarto del de los países avanzados. Las desigualdades de ingreso son más altas en los países del sur que en los del norte, salvo excepciones, y por lo tanto resulta que una fracción más o menos importante de la población de los países del sur tiene un ingreso medio cercano al de los países del norte.

Por un periodo largo, algunos países del sur, llamados emergentes, no presentan convergencia con los países del norte. El ejemplo de Argentina es, a este respecto, un caso emblemático de divergencia con los países avanzados durante un periodo largo. ${ }^{3}$ En el caso de México, de igual forma, mientras que la brecha entre el PIB por habitante disminuye con respecto al de Estados Unidos entre 1955 y 1980 , posteriormente aumenta. ${ }^{4}$ Se suceden fases de convergencia y de divergencia, sobre todo en los países latinoamericanos, mientras que en los países asiáticos la convergencia es más regular.

Sin embargo, salvo excepciones, en la década de 2000 el ingreso por habitante de numerosos países emergentes aumentó con mucha mayor rapidez que en los países avanzados. Desde 2010 ya no es así, con excepción, otra vez, de algunos países. La tasa de crecimiento de varios países latinoamericanos, en especial la de Brasil, se acerca hoy a la de los países avanzados, que se

${ }^{3}$ La marginalización de Argentina no es reciente. Mientras que en 1913 el ingreso per cápita de Argentina correspondía a 65\% del de Gran Bretaña, en 1945 se situaba aún en $60 \%$ y pasó, en 2001, a 39\%. La comparación con el ingreso per cápita de los españoles es todavía más elocuente: 393\% en 1913, 290\% en 1945 y $51 \%$ en 2001; el ingreso per cápita de los argentinos pasó así de ser el cuádruple del de los españoles a un poco más de la mitad.

${ }^{4}$ Véase J. A. Romero Tellaeche, Los límites al crecimiento económico de México, México, El Colegio de México / unam, 2014. 
caracterizan por una tendencia a la estagnación en Europa y Japón. Por lo tanto, ya no se trata de convergencia entre los niveles del PІв per cápita, sino entre las tasas de crecimiento del PIB, que es muy distinto. Éste aún no es el caso de China; su tasa de crecimiento disminuye aunque sigue siendo muy elevada, cosa que repercute en el crecimiento de los países latinoamericanos vía el descenso de los precios de las materias primas y el menos rápido aumento, o incluso el descenso, de las cantidades exportadas. El año 2010 abrió el camino para una nueva fase. Los patrones de crecimiento tanto en China como en Brasil se agotan; se dibujan nuevos patrones de crecimiento pero tienen dificultades para emerger.

China y Brasil tienen aspectos comunes y otros, más numerosos, muy distintos.

\subsection{Lo que asemeja a China y a Brasil es menos importante que lo que los diferencia}

Lo que asemeja a China y a Brasil: 1) una distribución de ingresos muy desigual, inequidades que se acentúan en China y que en Brasil disminuyen ligeramente, aunque siguen siendo extremadamente elevadas; 2) la situación de sus cuentas externas: las balanzas comerciales de China y de Brasil, hasta 2013, presentan un saldo positivo; 3) brechas en la productividad laboral entre empresas -según sus dimensiones- mucho más pronunciadas que en los países avanzados; lo mismo sucede con los salarios; ${ }^{5}$ 4) un crecimiento de sus tasas de salario medio superior a las de su productividad en ambos países; 5) niveles de corrupción elevados y una opacidad importante en las decisiones gubernamentales.

Lo que los diferencia:

1) La demografía: China (casi 1400 millones de habitantes en 2013) está altamente poblada, y Brasil, menos (203 millones para

${ }^{5}$ OCDE: http:/ /www.oecd.org, Economics Surveys: China, 2013; Economics Surveys: Brazil, 2013; véase también, con la CEPAL: Latin American Economic Outlook, 2013. 
la misma fecha), lo que repercute en las dimensiones de sus respectivos mercados interiores, principalmente en lo que concierne a las clases medias atraídas por productos sofisticados cuyas condiciones de producción exigen la creación de economías de escala importantes. La tasa de crecimiento demográfico en 2011 es del orden de $0.48 \%$ en China y de $1.1 \%$ en Brasil, según el Instituto Nacional de Estadística y Estudios Económicos (INSEE, por sus siglas en francés). La cuestión demográfica, por lo tanto, se va a convertir en un problema preocupante en China en los próximos años. Las proyecciones demográficas hechas en 2010 indican una caída sensible de la proporción de población en edad de trabajar (15-64 años)/población no activa. Si todo permanece igual, China deberá alcanzar para 2050 la proporción que presentaba en 1980, es decir, de 1.6. Con una cifra tal resulta difícil para la gente activa financiar las pensiones de las personas mayores y la educación de los jóvenes menores de quince años. La pirámide de edad se convierte en un obstáculo para alcanzar el crecimiento: cada vez menos jóvenes y cada vez menos mujeres. ${ }^{6}$ Lo que explica en parte que China regrese ahora a la política del hijo único.

2) La tasa de crecimiento en China era muy elevada y relativamente regular en la década de 2000 (entre 9 y 11\% anual); en Brasil es mucho más débil y relativamente volátil (4\% en promedio), pero un punto porcentual más alto que en la década de 1990, lo que repercute en la movilidad social.

3) La tasa de inversión en China es dos veces y media más alta que la de Brasil. La tasa de inversión es un buen indicador de la relación de los empresarios con el tipo ideal del emprendedor schumpeteriano. En China, las relaciones entre el Estado y los empresarios, ya sean privados o públicos, estimulan tasas de inversión elevadas. El enriquecimiento autorizado, sean cuales sean las

${ }^{6}$ Mientras que la tasa de hombres (proporción de nacimiento de hombres por cada cien mujeres) se estima en 1.05 para los países avanzados, en 1990 fue de 1.15, en 2000 de 1.17 y en 2005 de 1.2. En las sociedades asiáticas se prefiere tener más hombres que mujeres por diversas razones (la dote por ejemplo); la generalización de los ultrasonidos abre la puerta a los abortos para detener la llegada de hijas, sobre todo cuando entra en juego la restricción del hijo único. 
condiciones laborales, impulsa a invertir más y, con la corrupción que a menudo va aparejada, es una forma de controlar a los empresarios. En Brasil, la debilidad de la tasa de inversión es un indicador del carácter cada vez más rentista de la economía. La corrupción es más predadora que colbertista. Ciertamente, el enriquecimiento proviene de la explotación, pero también -y cada vez en mayor medida- de la búsqueda de ingresos que se obtienen mediante la explotación de materias primas o de la especulación financiera.

4) Una política de tipo de cambio diferente: en China el tipo de cambio está controlado y se mantiene a un nivel subvaluado; en Brasil se supone que debe ser libre y está apreciado. En China las inversiones de portafolio por el momento están prohibidas, salvo en ciertas zonas de experimentación desde hace poco tiempo; en Brasil son libres. En fin, en China las tasas de interés son relativamente débiles mientras que las de Brasil están entre las más elevadas del mundo.

5) La especialización internacional: China exporta sobre todo productos manufacturados y ocupa un lugar significativo en las exportaciones mundiales ( $12.1 \%$ en 2013 contra $1.2 \%$ en 1983). En pocos años se ha convertido en "el taller del mundo" y desde 2013 sus exportaciones e importaciones superan las de Estados Unidos. Con las exportaciones chinas que superan ampliamente sus importaciones, sobre todo a partir de su afiliación a la Organización Mundial de Comercio en 2001, y con sus entradas netas de inversión extranjera directa, las reservas chinas en divisas se vuelven considerables. El peso de Brasil en los intercambios internacionales permanece estable; idéntico en 1983 al de China, es decir $1.2 \%$ de las exportaciones mundiales, su porcentaje en 2013 es de $1.3 \%$. Brasil se abre al ritmo del crecimiento mundial de intercambios mientras que China lo hace doce veces más rápido. Brasil exporta relativamente cada vez menos productos manufacturados (52.1\% en 2005 y $35 \%$ en 2013 del total de sus exportaciones) y cada vez más productos primarios. Su comercio exterior está cada vez más orientado a Asia -con China como cliente principal- y cada vez menos hacia América Latina; de esta forma, se reprimariza. La reprimarización es precisamente el regreso hacia una 
estructura de exportación que privilegia cada vez más la exportación de productos primarios en detrimento de productos industriales. Desde ese punto de vista, su nueva inserción en la división internacional del trabajo se parece mucho a la antigua: exportación de materias primas poco trabajadas e importación de bienes manufacturados. No obstante, hay una excepción muy importante: la producción de materias primas exportadas, ya sean agrícolas o mineras, utiliza técnicas de producción sofisticadas que necesitan poca mano de obra.

6) El saldo de las balanzas de cuenta corriente: en China es positivo; en Brasil es profundamente negativo y se sitúa alrededor de los 80000 millones de dólares en 2014.

7) Estos últimos años China invirtió $13 \%$ de su PIB en infraestructura; por lo tanto, este rubro está en rápido desarrollo, sobre todo en lo que concierne a los transportes (China cuenta hoy con más kilómetros de vías férreas destinadas a trenes de gran velocidad que toda Europa junta, y se espera que alcancen los $16000 \mathrm{~km}$ para 2020). En Brasil la infraestructura es muy insuficiente y constituye un obstáculo para el aumento de la tasa de crecimiento. Según los datos del Banco Mundial, completados por Crédit Suisse (Research Institute: Latin American: the Long Road, febrero de 2014), el gasto en infraestructura representa en promedio el 2.19\% del PIB entre 1993 y 2003 (1.49\% en México), retrocede ligeramente entre 2003 y 2012 y se sitúa en un promedio de $2.13 \%$ del PIB. ${ }^{7}$

8) La tasa de urbanización: en China es modesta pero va en rápida progresión; en Brasil es muy alta, ligeramente superior a la de los países avanzados.

9) La violencia: la tasa de homicidio en China sigue siendo débil pero va en aumento; en Brasil sigue siendo muy alta en promedio, a la baja en los estados del sur y a la alza en los del norte.

${ }^{7} \mathrm{Al}$ contrario, en México el gasto en este rubro aumenta durante ese periodo: $3.95 \%$ en promedio, aunque con un desplome entre 2001 y 2006. Véase Ros Bosch, Algunas tesis equivocadas sobre el estancamiento económico de México, México, El Colegio de México, unam, 2013, p. 129. 


\section{2. ¿CUÁles SON lOS ASPECTOS POSITIVOS Y NEGATIVOS DE ESAS TRAYECTORIAS ECONÓMICAS RECIENTES?}

El desarrollo económico no se da en un contexto político semejante en China y en Brasil. China pasó de un modelo de dominación política de tipo dictatorial a uno autoritario. Como subraya M. C. Bergère, ${ }^{8}$ para muchos economistas y politólogos chinos el régimen autoritario no se funda sobre la legitimidad ideológica, sino sobre su eficacia. En Brasil, las dictaduras militares (1964-1967, 1967-1979) son muy eficaces si se las mide con la vara de las transformaciones económicas y del fuerte crecimiento. Sin embargo, con la abertura (apertura política en 1979), la democracia deberá administrar las consecuencias del milagro económico (crisis de la deuda en 1981, hiperinflación hasta 1994, aumento de las desigualdades de ingreso y de la pobreza, nulo crecimiento en la década de 1980). La crisis se supera, la hiperinflación se erradica en 1994, la situación en su conjunto mejora, la tasa de crecimiento aumenta moderadamente, las desigualdades entre ingresos retroceden ligeramente y la pobreza disminuye con fuerza. En un contexto de dificultades económicas más o menos importantes entre 1994 y 2004, la vía democrática, en lugar de perecer, conoce un proceso de consolidación a pesar de que la fosa entre la democracia formal (la de las urnas) y la democracia real (la de las desigualdades y el acceso a los derecho ${ }^{9}$ ) se mantenga, así como la incapacidad de aligerar la corrupción de las élites políticas y económicas.

Los aspectos positivos y negativos son relativamente escasos, lo que no significa que no sean importantes, todo lo contrario. En China se los puede agrupar en torno al crecimiento elevado, el equilibrio de los fundamentales (excedente de la balanza comercial, presupuesto equilibrado, cuasi pleno empleo, inflación controlada), el esfuerzo puesto en la infraestructura, la disminución de

${ }^{8}$ Bergère, Chine, Le nouveau capitalisme d'État, París, Fayard, 2013.

${ }^{9}$ D. Caputo, (dir.), La democracia en America Latina, Washington, PNUD, 2004, http:/ / www.undp.org; también: G. O’Donnell, "Acerca del estado en América Latina contemporánea: diez tesis para Discusión”, en D. Caputo (dir.), La democracia en América Latina, 2004. 
la pobreza; en Brasil, un crecimiento ligeramente más elevado que en los años noventa, un regreso al equilibrio de los fundamentales con excepción del equilibrio presupuestal, y la disminución de la pobreza. Los aspectos negativos son también escasos pero particularmente importantes en Brasil: la tasa de inversión, elevada en China, es ampliamente insuficiente en Brasil; la infraestructura -ahora abundante en China y relegada en Brasil- es un obstáculo para retomar el crecimiento en un modelo que no sea mediocre. No se tratará aquí el conjunto de los aspectos positivos y negativos, sino que se insistirá sobre algunos de ellos: crecimiento y movilidad social, inserción en la división internacional del trabajo y nuevas vulnerabilidades externas.

\subsection{Entre más alta sea la tasa de crecimiento, mayor es la probabilidad de que la movilidad social sea alta}

Más allá de las consideraciones exclusivamente productivistas, es importante considerar los efectos del crecimiento sobre la movilidad social. Matemáticamente, una tasa de crecimiento de $10 \%$ permite multiplicar el РІв por 28 en 35 años; una tasa de crecimiento de $2 \%$ sólo lo duplica. En los hechos, el piв per cápita de China, a tipo de cambio corriente, se multiplicó por poco más de 22 entre 1980 y 2011, pasó de 220 dólares en 1980 a 4930 dólares en 2011. Expresado a tasas de paridad de poder adquisitivo (PPA) se multiplicó por 33 según el Banco Mundial (Indicadores de desarrollo mundial, junio de 2012). Si se consideran los treinta años más favorables desde el punto de vista del crecimiento, China es el país que presentó el mayor crecimiento según el informe económico de la ocDe sobre China (2013). De hecho, de 1982 a 2011, la tasa de crecimiento anual per cápita fue de $9.15 \%$, mientras que en Corea (1966-1995) fue de 7.68\%, en Taiwán (1963-1992) de $6.87 \%$ y en la India (1982-2011) de $4.3 \%$.

Cuando la tasa de crecimiento es muy alta y relativamente regular, la movilidad social es fuerte. La probabilidad de que un niño proveniente de una familia pobre siga siendo pobre de adulto es débil, incluso si las desigualdades aumentan considerablemente 
como en el caso de China. Se desencadena mecánicamente una importante reducción de la pobreza: la pobreza, definida a partir del umbral de 2 dólares (PPA) diarios de 2005, pasó, así, de $98 \%$ de la población en 1980 a $30 \%$ en 2011 , y la pobreza extrema (menos de 1.25 dólares PPA) de 84 a $13 \%$ en el mismo periodo. ${ }^{10}$

La originalidad del modelo chino radica en la capacidad de mezclar el agua y el aceite: el mercado y el "socialismo". ${ }^{11}$ El sector privado se desarrolló con fuerza. No se limita a las actividades de las firmas extranjeras multinacionales. Sin embargo, el sector público conserva su importancia tanto en el terreno de las finanzas, como en el de la energía y la industria. Según el mismo informe de la OCDE, el valor agregado de las empresas controladas por el Estado en el sector industrial era de $44 \%$ del valor agregado industrial en 1998, y de 30\% en 2012. El número de empresas industriales controladas por el Estado, entre las mismas fechas, disminuyó con mayor fuerza: de $40 \%$ del total a $5 \%$, y el porcentaje de los asalariados de esas empresas pasó de 62 a 20\%. Dichas evoluciones reflejan también el fuerte proceso de modernización de las empresas controladas por el Estado puesto en marcha estos últimos veinte años.

La modernización de las empresas del sector público y de una parte del sector privado se financia con créditos a tasas de interés muy bajas y numerosas subvenciones. Las empresas que no se benefician de esta ayuda estatal se ven orilladas a pedir préstamos a tasas de interés altas y sufren así una "represión financiera".

La liberalización de los precios no implica, generalmente, el abandono de la propiedad pública. Los precios agrícolas hoy son casi todos libres, pero los campesinos no tienen más que el usufructo de la tierra que cultivan. Los precios de los bienes industriales -en el sentido amplio- en el presente son más o menos libres. Esta liberalización es progresiva, controlada por los poderes públicos, incluso cuando se traduce en el abandono de la propiedad pública; no es el resultado de un "big bang", como sucedió con el estallido

10 oCDE, Economics Surveys: China, 2013, http://www.oecd.org

${ }^{11}$ Más precisamente eso que los chinos (y otros) llaman socialismo, a saber, planificación impuesta y partido único. 
de la URSS y de los llamados países satélite. Luego de un periodo de transición más o menos largo, el precio de los bienes destinados a la demanda final depende en general de la ley del mercado. Por el contrario, los bienes intermedios se siguen beneficiando de gran cantidad de subvenciones y sus precios permanecen más controlados. La liberalización de los precios es todavía más débil cuando se trata de "factores de producción" como las materias primas. En fin, la economía china se caracteriza también por las facilidades de financiamiento acordadas para comprar empresas extranjeras -con el objetivo de apropiarse las tecnologías más recientes-, por cierto proteccionismo vía el mantenimiento de un tipo de cambio depreciado y la exclusión de facto, hoy, de las empresas extranjeras de las licitaciones públicas.

La política económica en China pretende flexibilizar el aparato de producción, integrar cada vez más las líneas de producción gracias a la producción de insumos locales (productos intermedios y bienes de equipamiento), dominar las nuevas tecnologías y aumentar la gama de productos destinados al mercado interior, y en menor medida, aquellos destinados a los mercados externos. Es por esto que China tiende a oponerse, con mayor o menor éxito, ${ }^{12}$ a las estrategias de las empresas extranjeras multinacionales que buscan optimizar la segmentación de la cadena de valor en el plano internacional, asunto que se tratará en la última parte.

La originalidad de ese modelo también se funda en:

- Una tasa de crecimiento elevada capaz de legitimar el sostenimiento de un régimen autoritario a pesar de la distribución particularmente desigual de los frutos del crecimiento y el despegue de la corrupción.

- La capacidad del Estado central de mantener el control político sobre los gobiernos de las provincias y dejarles cierta autonomía a las colectividades locales.

- La articulación de las fuerzas sociales bajo el escudo del Partido Comunista: empresarios de los sectores público y privado que generalmente pertenecen al Partido, el mundo laboral con

12 X. Richet, "L'internationalisation des firmes chinoises", en Slama (dir.), "Emergents: le temps des désillusions", Tiers Monde, núm. 219, pp. 59-77. 
sus diferencias cada vez más fuertes entre campo y ciudad, trabajadores calificados y no calificados, trabajadores residentes y trabajadores migrantes del campo (“mingongs") sin permiso ("hukou”), que muy poco se benefician de las ventajas sociales. Estos últimos, muy numerosos (260 millones), se concentran en los empleos no calificados y particularmente lamentables.

La intervención masiva del Estado, generalmente indirecta, la vulnerabilidad de los empresarios privados y públicos, la corrupción, la sobreexplotación de los trabajadores, sobre todo de los "indocumentados", son particularidades de este modelo. De hecho, se está ante un doble proceso de acumulación primitiva, el primero, en el sentido de Marx, con el influjo de campesinos pobres a las ciudades; el segundo, más complejo, con la expoliación de los ahorradores por las tasas de interés bajas, incluso negativas, y la concesión de crédito a tasas bajas para empresas seleccionadas, públicas y privadas. ${ }^{13}$

\subsection{Entre menos alta sea la tasa de crecimiento, menor es la probabilidad} de que la movilidad social sea considerable y grande, salvo si la distribución del ingreso se vuelve menos desigual

El aumento del gasto social (educación, salud), una modificación del sistema fiscal asociado a una política redistributiva y, finalmente, la recuperación del crecimiento, son las condiciones que pueden permitir una verdadera movilidad social. Si alguna de esas condiciones no se satisface, la probabilidad de que un niño proveniente de una familia pobre pueda salir de la pobreza se explica esencialmente por la posibilidad de convertirse en cantante, jugador de fútbol, político o mafioso, siempre y cuando brille por su excelencia en cualquiera de esos oficios. Cuando la tasa de crecimiento es moderada, como en el caso de Brasil, la probabilidad de que un niño proveniente de una familia pobre siga siéndolo en la edad adulta es relativamente alta, salvo si se da una modificación en la curva de

13 P. Salama, Les économies émergentes latino-américaines, entre cigales et fourmis, París, Armand Colin, collection U, 2012. 
Lorentz en favor de los deciles más bajos. Como sucedió en la década de 2000: la pobreza disminuyó gracias al aumento sustancial del salario mínimo en mucho mayor medida de lo que aumentó la productividad laboral. Es dicho aumento del salario mínimo y sus efectos sobre el funcionamiento del mercado de trabajo y sobre el cálculo de las pensiones lo que explica a la vez la reducción de las desigualdades en el ingreso y la disminución de la pobreza, mucho más que las transferencias monetarias que, contrario a la idea extendida, influyen sobre todo en la profundización de la pobreza. En el caso de Brasil, el efecto redistributivo compensa en parte el efecto insuficiente del crecimiento.

TABLA

Tasa de crecimiento del PIB de Brasil, 2001-2014

En \% 20012002200320042005200620072008200920102011201220132014 *

$\begin{array}{lllllllllllllll}\text { Brasil } & 1.3 & 2.7 & 1.2 & 5.7 & 3.2 & 4 & 6.1 & 5.7 & -0.7 & 7.5 & 2.7 & 0.9 & 2.3 & 0,17\end{array}$

Fuente: “Global Economic Prospect 2014”, Bradesco para 2014.

\subsection{Una nueva vulnerabilidad externa en Brasil, ¿̨el regreso del} "stop and go"?

Uno de los aspectos positivos importantes de este periodo es el saldo positivo de la balanza comercial. En Brasil, gracias a la creciente exportación de materias primas, el saldo de la balanza comercial se vuelve positivo después de 2001, y alcanza, según Bradesco, 46500 millones de dólares en 2006. Luego el saldo decrece y en 2013 es sólo de 2500 millones de dólares, es decir, casi veinte veces menor, y se vuelve negativo en 2014 (-700 millones de dólares). Hasta 2012, esta fuerte reducción se debe al declive relativo de las exportaciones de productos industriales. A partir de 2014, la disminución del valor de las exportaciones de materias primas y la de los productos manufacturados explican la aparición del saldo negativo ese año. 
Durante varios años, el saldo positivo de la balanza comercial y la entrada de capitales compensaron de sobra la salida de divisas por el pago de deuda, el reparto de dividendos y otros servicios, de suerte que las reservas internacionales aumentaron. Desde 2010 sucede de otra forma. La reducción drástica del saldo de la balanza comercial, la salida de capitales por el pago de dividendos y la repatriación de ganancias, conllevan un sensible aumento del déficit de la balanza de cuenta corriente. Después de haber sido excedentario entre 2003 y 2006, el saldo de la balanza de cuenta corriente se degrada progresivamente hasta alcanzar los -83400 millones de dólares en 2014 (3.6\% del PIB) según Bradesco, es decir, una caída de casi 100000 millones de dólares con respecto al excedente de 14000 millones de dólares alcanzado en 2005. La entrada neta de capitales, aún masiva gracias sobre todo a la inversión extranjera directa (64000 millones de dólares en 2013) y a la inversión de portafolio (25500 millones de dólares), compensa cada vez con mayor dificultad dichos déficits crecientes de la balanza de cuenta corriente. La vulnerabilidad externa de Brasil, por lo tanto, no desaparece. Cambia de forma. Ahora depende fundamentalmente de las materias primas, del precio, del volumen intercambiado ${ }^{14}$ y de la entrada de capitales de la que cierta parte puede ser demasiado volátil.

${ }^{14}$ La situación de Brasil difiere de la de México en sus relaciones con China. El saldo positivo de los intercambios con China disminuye con fuerza en razón de sus importaciones en alto crecimiento y de la disminución relativa de sus intercambios, que se atribuye a la reducción del crecimiento de China. México exporta pocas materias primas a China. Sus exportaciones pasaron de 204 millones de dólares en 2000 a 5700 millones de dólares en 2012, una progresión alta, pero entre las mismas fechas sus importaciones de China pasaron de 11300 millones de dólares a 56900 millones de dólares. Por lo tanto, el déficit con China es consecuente y se aproxima a los 50000 millones de dólares. Véase E. Dussel Peters, "La inversión extrajera directa de China en México. Los casos de Hawei y Giant Motors en Latinoamérica", en E. Dussel Peters (ed.), La inversión extranjera directa de China en América Latina: 10 estudios de caso, Unión de Universidades de América Latina y el Caribe, 2014, pp. 273-289; véase también el mismo autor con Gallagher, pero con datos ligeramente diferentes: E. Dussel Peters y K. P. Gallagher, "China's Economic Effects on the US-Mexico Trade Relationship. Toward a New Triangular Relationship?", en Dussel Peters, Hearn y Shaiken (eds.), China and the New Triangular 


\section{LOS ASPECTOS PROBLEMÁticos}

Se manifiesta un retroceso desde 2012. Ya no parece posible mantener el mismo modo de crecimiento que a principios de la década de 2000. El crecimiento disminuyó en los países emergentes, particularmente en América Latina. Se trata de las primeras manifestaciones del agotamiento de esos modelos. A China, convertida en "taller del mundo", le es cada vez más difícil cumplir ese papel. El crecimiento se busca mediante la capacidad de recuperar las cadenas de producción, de optar por especializaciones más eficientes dedicadas a productos más sofisticados con fuerte demanda potencial, en fin -y sobre todo-, de relativizar el papel del comercio exterior y de la inversión como principales contribuyentes de su crecimiento a favor de un mayor dinamismo de su mercado interior. Brasil intenta también dinamizar su mercado interior para reactivar su crecimiento, pero en un contexto totalmente diferente al de China. Con el regreso de las restricciones externas, una economía dependiente de la demanda sólo puede ser eficaz si logra una mejor competitividad. En China es necesario reducir la tasa de inversión, superar los problemas ligados a la baja de la rentabilidad en ciertos sectores vinculados a la capacidad de producción ociosa y financiar el servicio de la deuda de las empresas y de los municipios, siempre evitando que el peso de los créditos morosos, y las maneras de financiarlos vía shadow banking, precipite la

\footnotetext{
Relationships in the Americas: China and the Future of US-Mexico Relations, University of Miami / University of California / unam, 2014, pp. 13-35. México reúne a la vez una industrialización guiada por las exportaciones (las maquiladoras, a las que se puede añadir la industria automotriz, muy dinámica) y una desindustrialización del tejido industrial que viró hacia el mercado interior. Esto se explica por la falta de competitividad del país, aunque sus salarios hayan progresado durante la década, a diferencia de Brasil y Argentina, así como por la tasa de crecimiento extremadamente débil de su productividad laboral y por una política de apreciación de su moneda nacional, menos sistemática que en Brasil (Bresser Pereira, Mondialisation et compétition, pourquoi certaines économies émergentes réussissent et d'autres non ?, París, La Découverte, 2009; Salama, Les économies émergentes latino-américaines) o en Argentina (Damill, Frenkel y Rapetti, "The New Millennium Argentine Saga: from Crisis to Success and from Success to Failure", Working Paper, CEDEs, 2014), y sin embargo considerable (véase Romero Tellaeche, op. cit.; Ros Bosch, op. cit.).
} 
economía hacia un hard landing. En Brasil, pasar de una economía que se ha vuelto de nuevo globalmente rentista a causa del mayor peso de las materias primas y del auge de la financiarización obliga a abandonar la política cambiaria de sobrevaluación, de tasas de interés elevadas, a favor de una política industrial que sin esos prerrequisitos no podría ser eficaz, y de una verdadera reforma fiscal. Se comprende, pues, que tanto en un caso como en el otro, la solución no podría ser técnica: es sobre todo política. Las posibilidades de éxito de poner en marcha nuevas formas de crecimiento, y a la vez evitar que la transición sea demasiado accidentada, residen en la capacidad de superar las contradicciones que conllevarían estas medidas. Eso se verá a continuación.

\subsection{La dispersión de la cadena de valor, el aumento del comercio internacional y su ralentización}

La dispersión de la cadena de valor

En los años setenta, las deslocalizaciones de segmentos de producción involucraban a una empresa situada en un país avanzado y a una empresa que opera en un país menos avanzado; esta última podía ser una filial de la primera. Esas deslocalizaciones se explican por la ganancia obtenida al producir en países en vía de desarrollo, donde los salarios y los impuestos son más bajos, y el código laboral más laxo. Implican en general pocos productos, aquéllos por los cuales es posible optar por técnicas de producción labour-using.

Desde hace quince años, las deslocalizaciones se han multiplicado por tres razones: la baja de los costos intercontinentales de transporte, la revolución informática y la liberalización de los mercados. Este proceso, conocido como dispersión internacional de la cadena de valor, consiste en la fragmentación de la cadena de producción de un producto terminado en múltiples segmentos producidos en diferentes países. Eso provoca una cadena de importaciones y exportaciones que culmina en el ensamblaje final del bien en cuestión. ${ }^{15}$

${ }^{15}$ La producción del iPhone constituye un bello ejemplo de dispersión de la 
Las relaciones comerciales entre países son más densas, sobre todo entre países asiáticos, y explican en parte el auge del comercio sur-sur en el comercio mundial. ${ }^{16}$ Las relaciones entre Corea del Sur y China son emblemáticas de ese proceso; se multiplicaron por ocho entre 2002 y 2012. Tales relaciones siguen evolucionando: 1) Corea del Sur exporta bienes a China, quien, luego de transformarlos, los destina a la exportación. Como antes Corea del Sur, la China de hoy busca aumentar el valor agregado de los bienes destinados a su mercado exterior, oponiéndose así a la estrategia de dispersión de la cadena internacional de valor de las empresas

cadena de valor. La importación por parte de Estados Unidos del iPhone proveniente de China, donde se ensambla, representaba 1900 millones de dólares en 2012. Si se toma en cuenta la dispersión de la cadena de valor, el valor agregado de China se eleva solamente a 73.5 millones de dólares; en cambio, el de Japón se eleva a 684 millones, el de Corea del Sur a 259.4 millones de dólares, etc. (Carta IEDo, 2013). Desde un punto de vista macroeconómico, el ejemplo de México también es interesante. Hasta 2005, las exportaciones de las industrias de ensamblaje (maquilas) estaban contabilizadas como tales por México. Representaban $12.7 \%$ del PIB, pero si se toman en cuenta las importaciones necesarias para producirlas, la cifra obtenida es mucho más baja, el 2.9\% del PIв. Según Romero Tallaeche ( $o p$. cit.), esa proporción se mantiene más o menos estable hasta ahora. Los efectos de cluster son por lo tanto débiles y la integración, modesta, lo que explicaría que el aumento de la apertura no haya tenido los efectos de especialización esperados en un crecimiento que sigue siendo uno de los más mediocres de América Latina. Para otra apreciación, véase Carrillo (“¿De qué maquilas me hablas? Reflexiones sobre las complejidades de la industria de maquiladora en México", Revista Frontera Norte, vol. 26, núm. 3, 2013, pp. 75-97). Esta divergencia de apreciación puede explicarse en parte por el parámetro elegido, más difícil de evaluar a causa de la generalización de las medidas en favor de las industrias exportadoras que desembocaron en que ya no se sabe exactamente cuáles son las empresas maquiladoras y cuáles no lo son. Si se introduce por ejemplo el sector automotriz en las maquilas, entonces la parte de la integración es más importante; si se le excluye bajo pretexto de que su producción está en parte destinada al mercado interior, entonces el nivel de integración de ese tipo de industria baja y hallamos los datos de Romero Tallaeche. Y en el mismo tenor: es porque después de la modificación de la reglamentación de 2006 todas las empresas que exporten pueden ser consideradas maquilas, que la US International Trade Commision (2011) considera que el nivel de integración de México sería más elevado que el de China.

16 BID, 2013. WTO: http://www.wto.org, véase en especial: International Trade Statistics, 2014. 
multinacionales. 2) Corea también exporta bienes destinados al mercado interior chino, pero, tomando en cuenta la disminución de la brecha de competitividad entre los dos países, esa estrategia se torna más difícil. En efecto, China multiplica sus esfuerzos de investigación y desarrollo y su brecha tecnológica con Corea del Sur tiende a disminuir. Ésta fue de cinco años en 2002 y de tres años en 2012, según la revista Conjoncture de BNP Paribas (diciembre de 2013).

De una manera general, es más sencillo para el gobierno chino imponer una localización nacional de los insumos a las firmas multinacionales que producen sobre todo para su mercado interior que para aquéllas que producen casi exclusivamente para exportar. Más sencillo, pues el atractivo del vasto mercado interior chino es tan grande que las empresas multinacionales están dispuestas a: 1) interiorizar segmentos de producción, con la condición de que estos últimos respondan a normas de calidad; 2) autorizar los joint ventures, condición sine qua non para entrar en esos mercados; 3) autorizar la transferencia de tecnología, incluso las expoliaciones de los derechos de propiedad. Sin embargo, esa estrategia de localización no es simple: a pesar del esfuerzo en materia de educación y de investigación, de compra de firmas en países avanzados, la capacidad de producir insumos de alta calidad y lo suficientemente sofisticados para entrar en los procesos es más difícil de lo imaginado. ${ }^{17}$ En fin, imponerla a las firmas extranjeras exportadoras es más difícil, pues es común que estén especializadas en actividades de ensamblaje donde el costo de mano de obra es una variable importante. El alza acelerada de los salarios reales, las apreciaciones homeopáticas del renminbi en relación con el dólar, desembocan en un alza del costo unitario del trabajo a pesar del aumento importante de la productividad laboral. Numerosas empresas multinacionales buscan desde entonces relocalizarse en otros países (Bangladesh, Vietnam, la India) donde la mano de obra sigue siendo más barata, donde los códigos laborales laxos autorizan condiciones laborales indecentes, e incluso relocalizarse en Estados Unidos.

${ }^{17}$ Richet, art. cit. 
El despegue del comercio internacional seguido de una ralentización

A partir del comienzo de los años noventa, según los datos de la UNCTAD, la apertura se incrementó fuertemente. Entre 1987 y 2007 , víspera de la crisis, la tasa de crecimiento del comercio internacional fue en promedio de $7.1 \%$, es decir, más del doble de la del PIB mundial. Con la crisis desatada en 2008 y 2009, esa tasa bajó demasiado y después se recuperó ( $1.4 \%$ en 2010 y $5.8 \%$ en 2011), y disminuyó con fuerza a partir de 2012 (2.8\%) y 2013 $(2.8 \%)$, para situarse cerca de la tasa de crecimiento del PIB mundial, según la omc. ${ }^{18}$

La proporción de las exportaciones totales de bienes y servicios del PIB mundial se elevó a $20 \%$ en 1993, y a $33 \%$ en 2010, lo que implica un crecimiento de 13 puntos porcentuales en 17 años. Si bien se mantuvo muy elevada, es sin embargo menos importante de lo que los datos sugieren. Éstos sobrestiman la amplitud de los intercambios a causa de la multiplicación de las exportaciones de bienes intermedios que resulta de la fragmentación internacional de la cadena de valor. Por lo mismo, los economistas buscan hoy en día medir el valor agregado realmente exportado.

En el comercio internacional también el intercambio de servicios está en fuerte crecimiento. El intercambio de servicios ${ }^{19}$ es menos importante que el de bienes, pero tiene una progresión más acelerada. De hecho, los megacontratos incorporan una serie de servicios. En 2008, el total del intercambio internacional se descompone en $80 \%$ para los bienes y $20 \%$ para los servicios. Si se considera el valor agregado intercambiado y no la totalidad de las exportaciones tal como las declaran los países, la proporción de los bienes en la totalidad de bienes y servicios baja hasta $57 \%$, y la de los servicios sube a $43 \%$, contra el $20 \%$ anterior.

18 International Trade Statistics, 2014.

${ }^{19}$ Los servicios implican principalmente aquéllos ligados a los transportes, viajes, construcción, comunicación, seguros, servicios financieros, servicios informáticos, regalías. Los "nuevos sectores dinámicos": servicios ligados a la construcción, la informática, los servicios personales y culturales, las regalías, etc., tuvieron una fuerte progresión. 
A partir de 2010 asistimos a una fuerte disminución del intercambio internacional, que tuvo un ritmo inferior a la tasa de crecimiento del PIB. Esa disminución no se explica solamente por la baja de la demanda de los países avanzados -sobre todo europeos-, por el aumento -todavía tímido- del proteccionismo en ciertos países, ni por una transformación de la estructura del comercio donde los servicios ganan cada vez más terreno. Una relocalización parcial de las actividades de las firmas estadounidenses también se dio gracias a la utilización de nuevas técnicas, sobre todo las de las telecomunicaciones y la información, por una baja en el precio del petróleo gracias a la explotación del gas de esquisto, por una débil progresión de los salarios y, a contrario, por la fuerte alza de los salarios en China. Un éxito, aún tímido, de la estrategia del gobierno chino de localizar una parte de los insumos necesarios para su producción. Las causas de esa definición no serían, pues, solamente de orden coyuntural, sino también estructurales, según el FMI. ${ }^{20}$

\subsection{Una desindustrialización "precoz" en Brasil}

Particularidades de la desindustrialización "precoz"

Pasado cierto estadio de desarrollo, es usual constatar una baja relativa de la parte del sector industrial en el PIB a favor de los servicios; sin embargo, esto no implica necesariamente desindustrialización. El término desindustrialización generalmente está reservado para la baja absoluta del valor agregado de la industria o la reducción relativa del peso de la industria nacional en la industria mundial en economía abierta. No se ve eso en Asia. Se constata en la mayor parte de las economías avanzadas tras las numerosas deslocalizaciones y la dispersión geográfica de la cadena de valor, como hemos visto. En América Latina, este fenómeno tiende a intervenir mucho antes que en los países avanzados, de ahí la noción de "desindustrialización precoz". Se dice que es precoz porque el

${ }^{20}$ Véase "Slow Trade", en Finance et développement, marzo de 2014. 
ingreso per cápita al comienzo de ese proceso corresponde a la mitad del que tenían los países avanzados cuando comenzó su desindustrialización.

En Brasil, más allá del éxito de algunos sectores industriales como el aeronáutico, el automotriz y la industria petrolera, la desindustrialización se desarrolló en los años 2000. A diferencia de los países avanzados, la desindustrialización no fue el producto de deslocalizaciones masivas, sino de una destrucción parcial del tejido industrial. La desindustrialización es muestra a la vez de la pérdida de competitividad de la industria latinoamericana y del insuficiente nivel de infraestructura (vías férreas, puertos, aeropuertos, carreteras), incluso de la energía.

La participación de la industria de la transformación en la industria de la transformación mundial (en valor agregado) fue de $1.8 \%$ en 2005 y de $1.7 \%$ en 2011 , después de haber sido de $2.7 \%$ en 1980, según la base de datos de la UnCTAD (2013). De acuerdo con la misma fuente, en China era de $9.9 \%$ en 2005 y de $16.9 \%$ en 2011. Por lo tanto, dicha participación bajó relativamente en Brasil mientras que en China aumentó con fuerza. Las exportaciones de productos manufacturados disminuyeron en términos relativos en Brasil, pasando de 53\% del valor de las exportaciones en 2005 a $35 \%$ en 2012, en beneficio de las exportaciones de materias primas agrícolas y mineras.

A causa de la apreciación de la moneda con respecto al dólar y del alza de los salarios reales en moneda nacional en la década de 2000, los salarios expresados en dólares aumentaron rápidamente y pesaron sobre la competitividad del país. Así, según el reporte económico de la OCDE sobre Brasil, los salarios reales en dólares en Brasil pasaron de 4.35 dólares en 2000 a 8.44 dólares en 2006 y a 11.65 dólares en 2011. En comparación, en 2011 el salario real fue de 6.48 dólares en México y de 9.34 dólares en Taiwán.

En Brasil, la apreciación de la moneda nacional con respecto al dólar, la fuerte alza de los salarios (121\% entre 2002 y 2012, es decir, una media de $7.1 \%$ contra $8 \%$ en China) y el muy débil crecimiento de la productividad laboral (27\%, es decir $2.2 \%$ en promedio entre las mismas fechas) condujeron a un aumento del 
costo unitario del trabajo expresado en dólares de $158 \%$ entre las mismas fechas. ${ }^{21}$ Esa pérdida de competitividad explica en gran parte la desindustrialización de Brasil y el déficit de la balanza comercial de la industria de la transformación desde 2006.

El fin del alza del precio de las materias primas

El alza del precio de las materias primas y el aumento de los volúmenes intercambiados le permitieron a Brasil liberarse bastante de la presión externa y favorecieron los ingresos fiscales suplementarios. El excedente comercial, al que conviene añadir los ingresos netos de capitales importantes, favoreció una apreciación de la moneda nacional. Ésta generó un proceso de desindustrialización para los bienes intercambiables y a la vez un alza del precio de los servicios, que se manifestó con mayor frecuencia como una burbuja inmobiliaria. Esos efectos son conocidos y difícilmente evitables. Podrían serlo si se dieran, a la vez, una esterilización parcial de las entradas de divisas y una política industrial que favoreciera los productos de demanda muy elástica con respecto al ingreso más que a los precios. Estas políticas son difíciles de llevar a cabo por los conflictos que ocasionan.

A diferencia de otros países exportadores de materias primas, Brasil no gravó el volumen de ventas de las sociedades exportadoras y los ingresos fiscales suplementarios vienen del gravamen de sus ganancias. El matiz es importante. Significa que la baja de los precios y la disminución de los volúmenes intercambiados no implica una baja en los ingresos fiscales, salvo en lo que concierne a aquéllas que provienen de las ganancias. En ese sentido, Brasil es mucho menos vulnerable que países como Venezuela, Bolivia, Argentina $^{22}$ y México, donde aproximadamente $30 \%$ de los ingresos

${ }^{21}$ BBVA Research, documento de trabajo 14/10, marzo 2014.

${ }^{22}$ Los impuestos - "retenciones" en Argentina- son equivalentes a un sistema de tasa de cambio múltiple: la tasa oficial y una tasa apreciada para los exportadores de materias primas, ya que cada dólar obtenido se convierte en menos pesos. Esa política fiscal se enfrentó a la decidida oposición del sector del agrobusiness argentino y alimentó el conflicto distributivo entre ese sector y el gobierno. La situación de Brasil es distinta. A partir de 2003, a diferencia de Argentina, donde el 
fiscales depende de la venta de petróleo, los cuales representan aproximadamente $15 \%$ de las exportaciones. ${ }^{23}$

Desde hace aproximadamente dos años, al alza de los precios siguió una disminución más o menos importante según el tipo de materias primas exportadas. Comenzó con los metales, siguió con las oleaginosas y los cereales. Según el FMI, si tomamos el índice 100 para 2005, el índice para los metales era de 229.1 en 2011 y alcanzó 156.8 en octubre de 2014, y el de las oleaginosas, que era 209.1 en 2011, cayó a partir del comienzo de 2014 y se situó en 162.7 en octubre de $2014 .{ }^{24}$ Como hemos visto, la balanza comercial tuvo una reducción significativa de su saldo positivo, que se volvió ligeramente negativo a partir de 2014. La baja fue particularmente pronunciada en 2011. Las exportaciones de materias primas, cuyo peso en las exportaciones globales sobrepasa $63 \%$, bajaron de valor en $5.9 \%$ entre 2012 y 2013 , pero de noviembre de 2013 a noviembre de 2014 bajaron $18.7 \%, 25$ con que la alza disminuida de los volúmenes intercambiados no pudo compensar la fuerte baja de los precios.

No es común evocar un segundo efecto que podría designarse como efecto cremallera o, más aún, como efecto trinquete. Se trata del gasto público cuyo aumento algunas veces fue posible gracias al alza de los ingresos fiscales provenientes de la explotación de materias primas. Con la reducción del valor de las exportaciones de materias primas, los ingresos fiscales son mínimos, lo que puede conducir a una baja del gasto público, como frecuentemente sucedió en México. Es mucho más difícil reducir el gasto público que primero aumentarlo para después reducirlo con efectos

gobierno mantiene una tasa de cambio subvaluada, Brasil favorece una política de tasa de cambio apreciada. Ese tipo de impuesto no parece necesario, pues los ingresos netos en reales, que aumentan gracias a la política cambiaria, están gravados.

${ }^{23}$ Véase FMI, Arezki y Blanchard, diciembre 2014, "Siete cuestiones acerca de la caída reciente de los precios de petróleo".

${ }^{24}$ FMI: Comodity Market Monthly, noviembre 2014.

${ }^{25}$ Secretaría de Comercio Exterior, diciembre de 2014. A decir verdad, los bienes manufacturados, y particularmente los bienes de capital y de consumo durables, bajaron fuertemente también y mostraron la pérdida de competitividad descrita más arriba. 
recesivos conocidos. Hay por lo tanto un efecto trinquete, de ahí el término "cremallera", que evoca al tren de cremallera. Ese mecanismo solía resaltarse poco, pues los economistas insistían sobre todo en los efectos negativos del alza de los precios (la enfermedad holandesa). Y sin embargo se trata de un mecanismo análogo a la ley de Wagner (acumulación de las leyes y por lo tanto de las promesas de gasto, mientras que estos últimos no eliminan a los anteriores). Las razones son simples. Con el alza de los precios y de los intercambios, el gasto público se acrecentó y las necesidades así satisfechas no pueden suprimirse fácilmente, casi siempre por razones de legitimidad. Con la disminución, el déficit presupuestario se acentúa, y reducir el gasto para hacer que corresponda con el nivel de los ingresos acentúa a su vez el efecto recesivo, aumenta el déficit en porcentaje, del PIB y puede ser fuente de dificultades políticas.

A diferencia de la situación de los años 1950-1990, la industrialización está cediendo a la desindustrialización. También el mecanismo de reactivación por la devaluación de la moneda nacional es menos eficaz. La elasticidad de la oferta con respecto al precio, debilitado por la desindustrialización, es más débil que en el pasado, y la vuelta al equilibrio de la balanza comercial, que esta vez debe reposar en el despegue de las exportaciones industriales, se vuelve más aleatoria. Una dinámica perversa toma el lugar de la dinámica aparentemente virtuosa que la precedió, pero de la cual es, de hecho, la consecuencia directa.

\section{3. ¿Puede el mercado interior dinamizar el crecimiento?}

La pregunta hoy en día se hace tanto para Brasil como para China.

En América Latina, y particularmente en Brasil, para todo un conjunto de productos, la presión externa pesa cada vez más en forma de prerrequisitos en términos de competitividad. Ya que las condiciones cambiaron con la liberalización del comercio, el mercado interior no puede concebirse independientemente del mercado exterior para un conjunto de productos cada vez más importante. El 
crecimiento obtenido por el mercado interior no puede darse en Brasil a menos que las condiciones de competitividad sean respetadas globalmente, de lo contrario, el aumento de la demanda se traducirá en un alza de las importaciones, a menos que se vuelva al proteccionismo. Al aumentar las importaciones, debilita el crecimiento en vez de estimularlo.

Además, la dinámica del crecimiento por el mercado interior en Brasil necesita que se cumplan siete condiciones: 1) un crecimiento importante de la productividad del trabajo que disminuya el costo unitario del trabajo; 2) volver a poner en tela de juicio la lógica de las economías rentistas que limita la tasa de inversión a una cuota mínima; 3) una política activa que apunte a neutralizar la apreciación de la moneda; 4) una reforma fiscal que permita disminuir las desigualdades de ingresos y mejorar el poder adquisitivo de las categorías de la población pobre, vulnerable, y de las clases medias bajas (emergentes), y financiar servicios públicos de calidad (educación, salud, etc.); 5) una política que facilite a los pobres y a las clases vulnerables el acceso al crédito; 6) una política industrial activa del Estado que apunte a apoyar los sectores de vanguardia; y 7) una política de integración regional más activa a fin de aumentar el tamaño de los mercados. Que una de estas condiciones no se satisfaga vuelve más aleatorio el éxito de una política de crecimiento impulsada por el despegue del mercado interior.

En Asia, y particularmente en China, la respuesta a nuestra pregunta es relativamente diferente. Los costos unitarios del trabajo son bajos, aunque están creciendo en China hoy en día. Las políticas industriales son activas, la tasa de inversión importante y el esfuerzo por la investigación, consecuente. No se trata de economías rentistas.

El aumento del costo del trabajo, precedido por el de los salarios, para una tasa de crecimiento de la productividad laboral dada, disminuye la competitividad de las empresas que utilizan mucha mano de obra. Éstas prefieren entonces deslocalizarse hacia la India, Bangladesh o Vietnam. El agotamiento de las fuentes de crecimiento en China (crecimiento de las exportaciones más débil a causa de la crisis de las economías avanzadas, tasa de inversión revisada a la baja a causa tanto de los créditos morosos importantes 
como de la sobreproducción) impone que el crecimiento se impulse por el consumo de los hogares, de cualquier categoría. El mayor poder de las clases medias puede ahora ayudar a dinamizar el mercado interior gracias al despegue de la producción de bienes de consumo durables sofisticados. Es una de las posibilidades si se toma en cuenta la importancia de la población china. Existen otras soluciones, como un crecimiento impulsado por el consumo gracias a una sensible disminución de la desigualdad de ingresos. El aumento del consumo de todos los hogares, más que el de las clases medias, puede entonces conducir a un modelo de desarrollo más incluyente. Pero esa nueva orientación de la dinámica económica supone que se resuelva toda una serie de dificultades, de contradicciones dentro y entre las clases. ${ }^{26}$

Se podría considerar a priori que el riesgo financiero y bancario no es todavía demasiado elevado en China, pues la totalidad de los créditos que pesan sobre el PIB alcanzaba $154 \%$ en 2012, una cifra más baja que la de Estados Unidos en vísperas de la crisis de 2007 (224\%) o de Japón en vísperas de sus dificultades de 1989 (239\%). De hecho, el financiamiento del endeudamiento de las colectividades locales debido a las elevadas inversiones en infraestructura no se hace más que a través del crédito. Reposa también en los productos financieros complejos, es decir, las shadow banking activities de las instituciones financieras, muy poco controladas por las autoridades monetarias. El riesgo aumenta cuando se toma en cuenta el despegue de los productos financieros complejos. Éstos aumentaron $62 \%$ entre 2008 y 2012 y, si se toman en cuenta esas shadow banking activities, la proporción de la totalidad de créditos subió de $145 \%$ en 2008 a $207 \%$ en 2012, según los datos de la agencia Nomura. ${ }^{27} \mathrm{El}$ riesgo de una crisis financiera que pueda conducir a un "hard landing" es, pues, más elevado de lo que parece cuando se toman en cuenta los créditos excluyendo esos productos complejos.

${ }^{26}$ Véase Salama, Des pays toujours émergents?, La Documentation française, Collection Place aux débats, 2014, y del mismo autor, "Les classes moyennes peuventelles dynamiser la croissance du Рів dans les économies émergentes latino-américaines et asiatiques?”, en Salama (dir.), "Emergents : le temps des désillusions", Tiers Monde, núm. 219, 2014, pp. 141-159.

27 Asia Special Report, 2013. 
Ciertamente, los salarios han crecido en promedio más rápido que la productividad laboral desde 2009, pero la proporción del consumo en el PIB y su contribución al crecimiento todavía aumentan con demasiada lentitud. El despegue del consumo todavía podría venir por un ahorro negativo. Hasta hoy, la tasa de ahorro sigue siendo muy importante, pues los hogares chinos adoptan comportamientos precavidos relacionados con el costo de la salud, la educación, con las pensiones insuficientes y con la incertidumbre del empleo. La tasa de ahorro podría bajar y el consumo aumentar mañana si algunas reformas vieran la luz del día. Pero los problemas sociales, alimentados por la reducción del crecimiento, amenazan el equilibrio del poder político. El gobierno, buscando prevenir esos problemas, pretende ceder en algunos elementos cualitativos: reconocimiento del derecho a la propiedad de los campesinos, reconocimiento del buen fundamento de ciertas reivindicaciones de los trabajadores, puesta en marcha de un sistema de seguridad social más consecuente y accesible a los trabajadores "mingongs", anuncio de medidas de protección del medio ambiente fuertemente degradado. A estas medidas sociales se añaden otras que apuntan a limitar la amplitud de la corrupción que afecta al personal político y a los ejecutivos de las empresas en todos los niveles, a liberalizar progresivamente los movimientos internacionales de capital (limitados hoy en día a Shanghái, que sirve de zona experimental).

Será difícil poner en marcha las políticas económicas y sociales mencionadas. Las contradicciones entre los intereses del Estado central y los de las provincias, entre el sector público y el privado, entre los emprendedores y los asalariados, entre los asalariados sin documentos y los que sí los tienen, entre las autoridades locales y los campesinos que desean conservar sus tierras y que les reconozcan los derechos... se convierten en ecuaciones cada vez más difíciles de resolver de manera armoniosa en un país que cuenta con 1400 millones de habitantes, en el que los intereses de algunos cada vez se oponen más a los de los otros. El fracaso de una transición controlada no carecerá de efecto de contagio en los otros países, incluidos los avanzados. La ralentización de la actividad económica ya pesa fuerte sobre el equilibro de la balanza comercial y, de manera 
más moderada, sobre los ingresos fiscales. ¿Qué sucederá mañana si China se ve obligada a caer en la "trampa del ingreso medio", o peor, a afrontar un "hard landing"?

\section{Traducción de Hugo López Araiza Bravo y Ana Inés Fernández Ayala}

\section{Bibliografía y SITIOS CONSUltAdos}

Bergère, M. C., Chine, Le nouveau capitalisme d'État, París, Fayard, 2013.

Bresser Pereira, C., Mondialisation et compétition, pourquoi certaines économies émergentes réussissent et d'autres non?, París, La Découverte, 2009.

Caputo, D. (dir.), La democracia en America Latina, Washington, PNUD, 2004, http://www.undp.org

_, "Una agenda para la sustentabilidad de la democracia", Foreign Affairs, Washington, octubre-diciembre, 2005.

Carrillo, J., “¿De qué maquilas me hablas? Reflexiones sobre las complejidades de la industria de maquiladora en México", Revista Frontera Norte, vol. 26, núm. 3, 2013, pp. 75-97.

Carta IEDI, O lugar do Brasil nas cadeias globais de valor, núm. 578, 2013.

Damill, M., R. Frenkel y M. Rapetti, “The New Millennium Argentine Saga: from Crisis to Success and from Success to Failure", Working Paper, CEDES, 2014.

De la Cruz, J., R. Koopman y Whang Zhi, "Estimating Foreign Value-added in Mexico's Manufacturing Export", US International Trade Commission, 2011.

Dussel Peters, E., "La inversión extrajera directa de China en México. Los casos de Hawei y Giant Motors en Latinoamérica”, en E. Dussel Peters (ed.), La inversión extranjera directa de China en América Latina: 10 estudios de caso, Unión de Universidades de América Latina y el Caribe, 2014, pp. 273-289.

Dussel Peters, E. y K. P. Gallagher, "China's Economic Effects on the USMexico Trade Relationship. Toward a New Triangular Relationship?”, en E. Dussel Peters, A. H. Hearn y H. Shaiken (eds.), China and the New Triangular Relationships in the Americas: China and the Future of USMexico Relations, Center for Latin American Studies, University of 
Miami; Center for Latin American Studies, University of California, Berkeley; Centro de Estudios China-México, Facultad de Economía, UNAM, 2014, pp. 13-35.

Fabre, G., "La part du lion: les dessous du ralentissement économique chinois", en Salama (dir.), "Emergents: le temps des désillusions", Tiers Monde, núm. 219, pp. 39-59.

O’Donnell, G., "Acerca del estado en América Latina contemporánea: diez tesis para Discusión”, en D. Caputo (dir.), La democracia en América Latina, 2004.

Richet, X., "L’internationalisation des firmes chinoises", en Slama (dir.), "Emergents: le temps des désillusions", Tiers Monde, núm. 219, pp. 59-77.

Romero Tellaeche, J. A., Los límites al crecimiento económico de México, México, El Colegio de México, unam, 2014.

Rodrick, D., "Growth Strategies", en Ph. Aghion y S. Durlauf (dirs.), Handbook of Economic Growth, vol. 1, Elsevier, 2005.

Ros Bosch, J., Algunas tesis equivocadas sobre el estancamiento económico de México, México, El Colegio de México, unam, 2013.

Salama, P., Les économies émergentes latino-américaines, entre cigales et fourmis, París, Armand Colin, collection U, 2012 (traducción en curso; la primera versión de varios capítulos está disponible en español en mi sitio de internet).

— Des pays toujours émergents?, La Documentation française, Collection Place aux débats, 2014.

(dir.), "Emergents: le temps des désillusions", Tiers Monde, núm. 219.

_ , "Les classes moyennes peuvent-elles dynamiser la croissance du PIB dans les économies émergentes latino-américaines et asiatiques?”, en "Emergents: le temps des désillusions", Tiers Monde, núm. 219, 2014, pp. 141-159.

Asian Development Bank: http://www.adb.org

IEDI: http://www.iedi.org.br

IMF: http://www.imf.org

IPEA: http:/ / www.ipea.gov.br

Inter American Development Bank: http:/ / www.Iadb.org, véase en especial: After the Boom, Prospects for Latin America and the Caribbean in SouthSouth Trade, 2013. 
CEPAL: http:/ / www.eclac.org

OCDE: http://www.oecd.org, Economics Surveys: China, 2013; Economics Surveys: Brazil, 2013; véase también, con la CEPAL: Latin American Economic Outlook, 2013.

UNCTAD: http://www.unctod.org

World Bank: http://www.worldbank.org

wTO: http://www.wto.org 